\title{
Osteoarthritis of the hip: an occupational disease in farmers
}

\author{
Peter Croft, David Coggon, Marie Cruddas, Cyrus Cooper
}

\begin{abstract}
Objective-To test the hypothesis that farmers are at high risk of hip osteoarthritis and to investigate possible causes for such a hazard.

Design-Cross sectional survey.

Setting-Five rural general practices.

Subjects -167 male farmers aged $60-76$ and 83 controls from mainly sedentary jobs. All those without previous hip replacement underwent radiography of the hip.

Main outcome measures-Hip replacement for osteoarthritis or radiological evidence of hip osteoarthritis.

Results-Prevalence of hip osteoarthritis was higher in farmers than controls and especially in those who had farmed for over 10 years (odds ratio $9 \cdot 3,95 \%$ confidence interval 1.9 to $44 \cdot 5$ ). The excess could not be attributed to any one type of farming, and heavy lifting seems the likely explanation.

Conclusions-Manual handling in agriculture should be limited where possible. Consideration should be given to making hip osteoarthritis a prescribed industrial disease in farmers. There may be wider implications for the prevention of hip osteoarthritis in the general population.
\end{abstract}

\section{Introduction}

Osteoarthritis of the hip is an important cause of pain and disability in older people. In Britain, some 5\% of men and women over the age of 60 suffer symptoms severe enough to warrant total hip replacement, ${ }^{12}$ yet the aetiology of the disease is largely unknown. One possible cause is cumulative mechanical stress on the joint from physical activities such as heavy lifting, in which case a high incidence might be expected in occupations that entail frequent manual handling.

Evidence is emerging that one such occupationfarming - is associated with high rates of surgery for hip osteoarthritis..$^{3-6}$ Farmers may, however, obtain treatment more often than other occupational groups, not because they have a higher incidence of the disorder but because they are more handicapped by it when it occurs. It is important to establish whether there is a true occupational hazard so that preventive measures can be instituted and also because such knowledge might increase our understanding of pathogenesis.

We report a population based survey comparing the prevalence of hip osteoarthritis in male farmers and in controls from mainly sedentary jobs.

\section{Method}

Farmers and controls were identified by a screening postal questionnaire which we sent to 1231 men aged 60-76 selected at random from the lists of five rural general practices. Three of the practices were in the Staffordshire moorlands and two in lowland Cheshire. The questionnaire asked whether subjects had been employed for all or part of their working lives in any of five jobs-mining, quarrying, farming, office work, and pottery. (Mining, quarrying, and pottery are major local industries and were included to disguise the purpose of the questionnaire). As a check for response bias at later stages of the study we also asked whether subjects had ever suffered from pain in their shoulders, elbows, wrists, hips, or knees.

Replies were received from 890 men, a response rate of $72 \%$. A total of 289 reported having worked at some time in farming, and 123 said that they had spent their entire careers in office work. These men were selected for further investigation, and $288(70 \%)$ agreed to be interviewed and examined at home. Each participant was visited by one of three interviewers, who used a structured questionnaire to obtain a more detailed occupational history with emphasis on farming activities. Heights were measured with a Harpenden portable stadiometer, weights with Seca scales, and hands were examined for the presence of Heberden's nodes. Subjects were classified as having definite, possible, or no nodes as in an earlier study.

We also asked about previous hip disease and about any recent radiographic examination of the hips. When a hip replacement was reported this was confirmed by reference to hospital notes and a preoperative radiograph was sought. Where a radiograph showing the hips had been taken in the past six months the relevant film was reviewed. Subjects who had not had a hip replacement or a recent $x$ ray examination of the hips were invited to attend their local hospital for a plain anteroposterior pelvic radiograph to show both hip joints. A typical exposure was $70 \mathrm{kV} 25 \mathrm{~mA}$, giving an approximate skin dose of $1.5 \mathrm{mGy}$ and an effective dose equivalent to the whole body of $0.3 \mathrm{mSv}$. Approval was obtained from the ethical committee of North Staffordshire Health Authority.

Hip joints were assessed by measurement of minimal joint space - that is, the shortest distance between the femoral head margin and the acetabulum. Subjects were classified as having hip osteoarthritis if they had had a hip replacement for the disorder or if they had a minimal joint space $\leq 1.5 \mathrm{~mm}$ in at least one hip. The radiographs were assessed by a single observer without knowledge of the interview findings.

Associations between osteoarthritis and risk factors were examined by logistic regression. For analysis, continuous variables (height, weight, and Quetelet's index) were grouped into thirds of their distribution in the study sample.

\section{Results}

Assessment of osteoarthritis was possible in 250 subjects ( 179 farmers and 71 office workers). Twenty nine men declined $x$ ray examination and nine were too ill to attend hospital. Analysis of response rates according to lifetime history of hip pain as reported on the initial questionnaire showed that symptomatic farmers were somewhat overrepresented in the group that was
Correspondence to: Dr Coggon.

BMf 1992;304:1269-72 
assessed for osteoarthritis. They had a participation rate of $78 \%$ compared with $54 \%$ for asymptomatic farmers, $60 \%$ for symptomatic office workers, and $57 \%$ for asymptomatic office workers. The 179 farmers who underwent assessment included 12 who had worked in agriculture for less than one year. In subsequent analyses these men were treated as controls along with the 71 office workers.

Table I shows the prevalence of hip osteoarthritis according to age and occupational history. Within each age group osteoarthritis was noticeably more common among men who had farmed for at least one year than in controls. Of the 28 cases diagnosed in farmers, 20 had undergone hip replacement, as had one of the two cases from the control group. Preoperative radiographs were available for 15 of the men with replacements and in each case showed a joint space $\leq 1.5 \mathrm{~mm}$. The prevalence of osteoarthritis increased with age, and

TABLE I - Prevalence of hip osteoarthritis according to age and history of farming

\begin{tabular}{lccccccc}
\hline & \multicolumn{3}{c}{ Farmed for at least one year } & & \multicolumn{3}{c}{ Controls } \\
\cline { 2 - 3 } $\begin{array}{l}\text { Age } \\
\text { years })\end{array}$ & $\begin{array}{c}\text { No of men } \\
\text { assessed }\end{array}$ & $\begin{array}{c}\text { No of cases } \\
\text { (No with hip } \\
\text { replacement) }\end{array}$ & $\begin{array}{c}\text { Prevalence } \\
(\%)\end{array}$ & & $\begin{array}{c}\text { No of men } \\
\text { assessed }\end{array}$ & $\begin{array}{c}\text { No of cases } \\
\text { (No with hip } \\
\text { replacement) }\end{array}$ & $\begin{array}{c}\text { Prevalence } \\
(\%)\end{array}$ \\
\hline $60-65$ & 58 & $8(7)$ & $13 \cdot 8$ & & 37 & $1(0)$ & $2 \cdot 7$ \\
$66-70$ & 54 & $7(5)$ & $13 \cdot 0$ & & 26 & $0(0)$ & 0 \\
$71-76$ & 55 & $13(8)$ & $23 \cdot 6$ & & 20 & $1(1)$ & $5 \cdot 0$ \\
\hline
\end{tabular}

Summary odds ratio for farmers $v$ controls $=7 \cdot 8$ ( $95 \%$ confidence interval $1 \cdot 8$ to $33 \cdot 8)$.

TABLE II - Associations of hip osteoarthritis with height, weight, and Heberden's nodes

\begin{tabular}{|c|c|c|c|}
\hline Risk factor & $\begin{array}{l}\text { No of men } \\
\text { assessed }\end{array}$ & $\begin{array}{l}\text { No of } \\
\text { cases }\end{array}$ & $\begin{array}{c}\text { Odds ratio }(95 \% \\
\text { confidence interval }) \dagger\end{array}$ \\
\hline \multicolumn{4}{|l|}{ Height $(m)$ : } \\
\hline$<1.685$ & 79 & 7 & $1 \cdot 0$ \\
\hline $1 \cdot 685-1 \cdot 735$ & 80 & 7 & $1 \cdot 1(0.3$ to 3.3$)$ \\
\hline$>1.735$ & 88 & 15 & $2.8(1.0$ to 7.9$)$ \\
\hline \multicolumn{4}{|l|}{ Weight $(\mathrm{kg})$ : } \\
\hline$<73.5$ & 79 & 7 & $1 \cdot 0$ \\
\hline $73 \cdot 5-82 \cdot 5$ & 88 & 7 & $0.9(0.3$ to $2 \cdot 7)$ \\
\hline$>82 \cdot 5$ & 79 & 15 & $2.6(1.0$ to 6.9$)$ \\
\hline \multicolumn{4}{|c|}{ Quetelet's index $\left(\mathrm{kg} / \mathrm{m}^{2}\right)$ : } \\
\hline$<25 \cdot 4$ & 83 & 7 & $1 \cdot 0$ \\
\hline $25 \cdot 4-28 \cdot 3$ & 84 & 8 & $1.2(0.4$ to 3.5$)$ \\
\hline$>28 \cdot 3$ & 78 & 13 & $2 \cdot 0(0.7$ to $5 \cdot 5)$ \\
\hline \multicolumn{4}{|l|}{ Heberden's nodes: } \\
\hline Absent & 84 & 5 & $1 \cdot 0$ \\
\hline Possible & 73 & 7 & $1.6(0.5$ to $5 \cdot 3)$ \\
\hline Definite & 93 & 18 & $3.4(1.2$ to $10 \cdot 0)$ \\
\hline
\end{tabular}

$\star$ Because of problems with instrumentation heights were missing for three subjects and weights for four subjects.

tAdjusted for age in two year intervals.

TABLE III - Risk of osteoarthritis according to duration of farming

\begin{tabular}{lcccc} 
& & \multicolumn{2}{c}{ Odds ratio $(95 \% \text { confidence interval })^{\star}$} \\
\cline { 4 - 5 } & $\begin{array}{c}\text { No of subjects } \\
\text { assessed }\end{array}$ & $\begin{array}{c}\text { No of } \\
\text { cases }\end{array}$ & $\begin{array}{c}\text { Adjusted for age } \\
\text { alone }\end{array}$ & $\begin{array}{c}\text { Adjusted for all } \\
\text { variablest }\end{array}$ \\
\hline Controls & 83 & 2 & $1 \cdot 0$ & $1 \cdot 0$ \\
l-9 Years' farming & 52 & 6 & $5 \cdot 8(1 \cdot 1$ to $31 \cdot 5)$ & $\begin{array}{c}4 \cdot 5(0 \cdot 8 \text { to } 26 \cdot 3) \\
\geq 10 \text { Years' farming }\end{array}$ \\
\hline
\end{tabular}

*Adjusted for age in two year intervals.

tAdjusted for height (three strata), weight (three strata), and presence of Heberden's nodes (absent, possible, or definite).

TABLE IV - Risk of hip osteoarthritis in men who farmed for at least one year according to type of farming

\begin{tabular}{|c|c|c|c|c|c|}
\hline \multirow[b]{2}{*}{$\begin{array}{l}\text { Type of } \\
\text { farming }\end{array}$} & \multicolumn{2}{|c|}{ Exposed } & \multicolumn{2}{|c|}{ Not exposed } & \multirow[b]{2}{*}{$\begin{array}{c}\text { Odds ratio }(95 \% \\
\text { confidence interval) }\end{array}$} \\
\hline & $\begin{array}{l}\text { No of men } \\
\text { assessed } \dagger\end{array}$ & $\begin{array}{l}\text { No of } \\
\text { cases }\end{array}$ & $\begin{array}{l}\text { No of men } \\
\text { assessed } t\end{array}$ & $\begin{array}{l}\text { No of } \\
\text { cases }\end{array}$ & \\
\hline Arable & 71 & 9 & 91 & 17 & $1.0(0.3$ to $3 \cdot 1)$ \\
\hline Dairy & 13 & 1 & 149 & 25 & $1.9(0.2$ to 18.5$)$ \\
\hline Stock & 76 & 13 & 86 & 13 & $0.6(0.2$ to 1.7$)$ \\
\hline Sheep & 84 & 13 & 78 & 13 & $1.2(0.4$ to 3.5$)$ \\
\hline Root vegetables & 94 & 12 & 68 & 14 & $2.5(0.8$ to 8.3$)$ \\
\hline
\end{tabular}

*All types of farming were examined simultaneously in a single logistic regression model with allowance for age (in two year intervals), height (three strata), weight (three strata), and the presence of Heberden's nodes (absent, possible, or definite)

Excludes five men whose heights or weights were unknown

$\ddagger$ For men who carried out a type of farming relative to those who did not.
TABLE $\mathrm{v}-$ Occupational activities reported by farmers with and without hip osteoarthritis

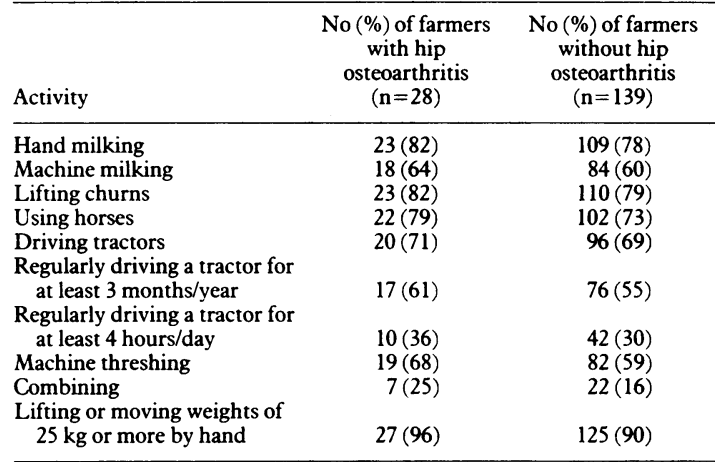

therefore in all further analyses risk estimates were adjusted for age in two year intervals.

Table II shows associations of hip osteoarthritis with height and weight. Risk was higher in the tallest and heaviest members of the study sample and also in those with the highest Quetelet's indices. In addition, the disease was significantly more common in subjects judged to have definite Heberden's nodes (odds ratio $3 \cdot 4,95 \%$ confidence interval $1 \cdot 2$ to $10 \cdot 0$ ).

Table III shows the relation of hip osteoarthritis to duration of farming. Risk increased with time spent working in agriculture such that in men who had farmed for more than 10 years disease was some eight times more prevalent than in controls. This excess was highly significant $(p=0.003)$. Because disease was quite common, odds ratios were generally higher than ratios of crude prevalence. Men who had farmed were somewhat shorter (mean height $1.710 \mathrm{~m} v 1.717 \mathrm{~m}$ ) and heavier (mean weight $80.5 \mathrm{~kg} v 77.2 \mathrm{~kg}$ ) than controls. They also had a higher prevalence of definite Heberden's nodes $(39 \cdot 5 \% \quad v \quad 32 \cdot 5 \%)$. However, odds ratios were little altered by adjustment for constitutional risk factors in addition to age.

The relation of osteoarthritis to specific types of farming is summarised in table IV. Among the men who had farmed for at least one year no single branch of agriculture stood out as being responsible for the excess of hip disease.

Table $\mathrm{V}$ shows occupational activities reported by the 28 farmers with hip osteoarthritis. Most of the activities examined had been carried out by many of the farmers at some stage in their careers. In particular, all but one reported regularly lifting or moving weights of $25 \mathrm{~kg}$ or more by hand. Eight had never driven tractors, and only 10 had regularly driven tractors for at least four hours a day.

\section{Discussion}

In this general population sample the prevalence of hip osteoarthritis was substantially higher in men who had farmed than in controls who had done mostly sedentary work. The excess was evident in a higher prevalence of joint space narrowing as well as of surgically treated disease and thus could not be explained by differences in propensity to seek medical care. Risk increased with duration of farming, such that the prevalence among men who had farmed for more than 10 years was eight times that in controls.

We think it unlikely that these findings can be attributed to biases in the study method. Since the preliminary postal questionnaire did not obviously focus on farming and hip disease, there is no reason why farmers with hip osteoarthritis should have replied more readily than men from other occupations. A more likely source of error was the differential response of subjects subsequently selected to undergo interview and radiographic examination. In particular, 
farmers with hip pain were overrepresented compared with office workers and farmers without hip symptoms. But even if there had been no further cases of hip osteoarthritis among the non-responding farmers, the overall prevalence in men who had ever farmed would still have been $9 \cdot 7 \%$-much higher than the $2 \cdot 8 \%$ recorded in responding office workers; and, if anything, responding office workers would be expected to have more disease than those who were not assessed.

The radiological criterion by which we defined cases of hip osteoarthritis - a minimal joint space $\leq 1.5 \mathrm{~mm}$-was based on earlier work which had shown that joint space measurement is repeatable within and between observers, and that a cut off point of $1.5 \mathrm{~mm}$ provides an index that is strongly associated with other radiological features of the disease and with symptoms. ${ }^{8}$ The sensitivity of the criterion is shown by the observation that this degree of joint space narrowing was found in all 15 surgically treated patients for whom preoperative radiographs were available. Using this definition, we found two cases of osteoarthritis among the 83 controls, a prevalence of $2 \cdot 4 \%$. This compares with a prevalence of $5 \cdot 1 \%$ in a consecutive series of 1315 intravenous urograms in men of the same age from the same area of England (including some farmers) (unpublished data); with prevalences of $2.0 \%$ and $4.5 \%$ for severe hip osteoarthritis among men of the same age group in population surveys from the United States ${ }^{9}$ and the Netherlands ${ }^{10}$; and with a prevalence of $3 \cdot 1 \%$ in Swedish male office workers (mean age 64 years). ${ }^{11}$ Although the last three studies used a different case definition, the similarity of the findings from all of the surveys suggests that our control prevalence is not a gross underestimate and that sedentary workers do not have an exceptionally low rate of the disease. Rather, the difference between farmers and controls seems to stem from a high prevalence in the farmers. Moreover, the excess was not explained by a confounding effect of height and weight or of generalised susceptibility to osteoarthritis as indicated by the presence of Heberden's nodes.

Other studies support the idea that farmers are at increased risk of hip osteoarthritis. Osteoarthritis was associated with a history of farming in a survey of Finnish patients who had undergone radiological examination of the hips, ${ }^{12}$ and in a Swedish casecontrol study men who had farmed for more than 10 years had a relative risk of 3.2 for surgically treated disease. ${ }^{5}$ Follow up of Swedish blue collar workers who had reported the same occupation at three successive censuses showed an almost fourfold increase in admission to hospital for hip osteoarthritis among farmers ${ }^{6}$; and a survey of Swedish farmers who had undergone radiographic examination of the urinary tract or colon found a prevalence of osteoarthritis more than 10 times that in general population controls. ${ }^{13}$ In Britain a casecontrol study which identified cases from intravenous urograms suggested a doubling of risk in men who had worked as farmers for 10 or more years. ${ }^{14}$ In conjunction with these findings our results constitute strong evidence for an occupational hazard.

The exact nature of the hazard is less clear. In addition to heavy lifting,,$^{14-16}$ possible explanations include exposure to whole body vibration from agricultural machinery ${ }^{15}$ and stress on the hip from walking over rough ground. ${ }^{14}$ To explore these and other possible mechanisms we collected detailed information about the types of farming that our subjects had carried out and the activities in which they had engaged. The relation of hip osteoarthritis to farming was not specific to any one type of agriculture (table IV), nor could it confidently be ascribed to any single farming activity (table V). Nevertheless, eight of the 28 farmers with osteoarthritis had never driven tractors or harvesters, which suggests that if whole body vibration does contribute to the disease excess it is not the only explanation. In contrast, all but one of the men reported having regularly lifted weights of over $25 \mathrm{~kg}$. Many commented that in their early years in agriculture they had lifted exceptionally heavy loads - for example, $21 / 2 \mathrm{cwt}(125 \mathrm{~kg}$ ) corn sacks and 17 gallon (75 litre) milk churns. However, we did not collect this information systematically. A problem in trying to discriminate between possible explanations for the hazard was the fact that most farmers had carried out a wide range of activities. The answer may come more easily from studies of other occupational groups who are exposed to either heavy lifting or whole body vibration, but not both. Several studies have suggested that risk is increased in other jobs that entail heavy lifting - for example, construction work. ${ }^{6} 1516$

Another question as yet unanswered is whether risk relates particularly to activities at an early age. Many of our subjects started farm work in their early teens, when the hip joint is still not fully developed. The hip may be particularly vulnerable to trauma or physical stress at this stage of life. Such stress is thought to cause slipped femoral epiphysis, for instance, which is commoner in rural areas ${ }^{17}$ and can lead to degenerative disease. ${ }^{18}$ Unfortunately, we were not able to test this hypothesis satisfactorily because age at starting farm work was strongly correlated with duration of employment in agriculture.

Until the reasons for the excess of hip osteoarthritis in farmers are clarified, preventive strategies can only be speculative. Because heavy lifting is also associated with other musculoskeletal disease, especially low back disorders, ${ }^{19}$ it makes sense to limit manual handling in agriculture as far as is reasonably practical. In addition, consideration should be given to making hip osteoarthritis a prescribed industrial disease in people who have farmed for a large part of their working lives.

Our data suggest that as many as one in five farmers may eventually require hip replacement. This is a big risk for a severely disabling disease. Furthermore, given that some 300000 men work in agriculture in Britain,,$^{20}$ and even more have done so in the past, it implies a major public health problem. If the risk is from heavy lifting it will not be confined to farmers, and the burden on the public health will be even greater. Opportunities to control such an important cause of disease must not be missed.

Peter Croft was in receipt of a Wellcome training fellowship in clinical epidemiology. We thank Ruth Hayton and Helen Wright, who carried out interviews; the doctors and staff of the five participating general practices; Dr Mike Braithwaite, Mary Swire, and the staff of the radiology departments in Stoke on Trent and Leek; Jan Cohen of the North Staffordshire Industrial and Community Health Research Centre; and Mrs Qing Mao, who helped with the computing.

1 Wilcock GK. The prevalence of osteoarthritis of the hip requiring total hip replacement in the elderly. Int f Epidemiol 1979;8:247-50

2 Frankel S, Williams M, Nanchahal K. Epidemiologically based needs assessment -total hip and knee joint replacements. Bristol: Health Care Evaluation Unit, University of Bristol, 1990

3 Louyot P, Savin R. La coxarthrose chez l'agriculteur. Rev Rhum 1966;33: 625-32.

4 Frank $O$, Klemmayer $K$. Die Koxarthrose bei der Landbevolkerung. Zeit Rheum 1968;27:371-9.

5 Thelin A. Hip joint arthrosis: an occupational disorder among farmers. Am F Ind Med 1990;18:339-43.

6 Vingard E. Work, sports, overweight, and osteoarthrosis of the hip [dissertation]. Stockholm: Karolinska Institute, 1991.

7 Croft $P$, Cooper $C$, Wickham C, Coggon D. Is the hip involved in generalised osteoarthritis? Brf Rheumatol (in press).

8 Croft P, Cooper C, Wickham C, Coggon D. Defining osteoarthritis of the hip for epidemiologic studies. Am F Epidemiol 1990;132:514-22.

9 National Center for Health Statistics. Basic data on arthritis of the knee, hip, and sacroiliac joints in adults aged 25-74 years. Washington, DC: GPO, 1979. sacroiliac joints in adults aged 25-74 years. Washington, DC:
(Series 11, No 213; DHEW publication No (PHS) 79-1161.)

10 Van Saase JLCM, Van Romunde LK, Cats A, Vandenbroucke JP, an Saase JLCM, Van Romunde LK, Cats A, Vandenbroucke JP,
Valkenburg HA. Epidemiology of osteoarthritis: the Zoetermeer survey. Valkenburg HA. Epidemiology
Ann Rheum Dis 1989;48:271-80.

11 Lindberg H, Danielsson LG. The relation between labor and coxarthrosis. Clin Orth 1984;191:159-61. 
12 Typpo T. Osteoarthritis of the hip. Ann Chir Gynaecol 1985;74(suppl 201): $1-38$

13 Axmacher B, Lindberg $\mathrm{H}$. Coxarthrosis in farmers as appearing on colon radiograms and urograms. In: Hogstedt C, Reuterwall C, eds. Progress in occupational epidemiology. Amsterdam: Excerpta Medica, 1988-203-6.

14 Croft P, Cooper C, Wickham C, Coggon D. Osteoarthritis of the hip and occupational activity. Scand $f$ Work Environ Health 1992;18:59-63.

15 Jacobsson B, Dalen N, Tjornstrand B. Coxarthrosis and labour. Int Orth $1987,11 \cdot 311-3$.

16 Vingard E, Hogstedt C, Alfredsson L, Fellenius E, Goldie I, Koster M. Coxarthrosis and physical work load. Scand $\mathcal{f}$ Work Environ Health 1991:17:104-9.
17 Hagglund G, Hansson LI, Ordeberg G. Epidemiology of slipped capital femoral epiphysis in Southern Sweden. Clin Orthop 1984;191:81-94.

18 Ordeberg G, Hansson LI, Sandstrom S. Slipped capital femoral epiphysis in Southern Sweden. Clin Orthop 1984;191:95-104.

19 Walsh K, Cruddas M, Coggon D. Interaction of height and mechanical loading of the spine in the development of low back pain. Scand $\mathcal{f}$ Work Environ Health $1991 ; 17: 420-4$.

20 Office of Population Censuses and Surveys. Occupational mortality: decennial supplement 1979-80, 1982-83. London: HMSO, 1986.

(Accepted 26 February 1992)
Department of Virology, United Medical and Dental Schools of Guy's and St Thomas's Hospitals, St Thomas's Campus, London SE1 7EH Anthea J Tilzey, senior registrar in virology Sara J Palmer, chief medical laboratory scientific officer Jangu E Banatvala, professor of clinical virology

SmithKline Beecham Pharmaceuticals, Welwyn Garden City

Susan Barrow, head of therapeutics

Helen Tyrrell, senior clinical trials scientist, medical department

\section{Virus Reference}

Laboratory, Central

Public Health Laboratory,

Colindale

Keith R Perry, clinical scientist

SmithKline Beecham Biologicals, Rixensart, Belgium

Assad Safary, group manager

(clinical research)

Correspondence to:

Professor Banatvala.

\title{
Clinical trial with inactivated hepatitis A vaccine and recommendations for its use
}

\author{
Anthea J Tilzey, Sara J Palmer, Susan Barrow, Keith R Perry, Helen Tyrrell, Assad Safary, \\ Jangu E Banatvala
}

\begin{abstract}
Objective-To compare the reactogenicity and immunogenicity of an inactivated hepatitis $A$ vaccine in two different immunisation schedules.

Design-Randomised trial.

Setting-One London teaching hospital.

Subjects-104 healthy adult volunteers (71 men, 33 women aged 19-60).
\end{abstract}

Interventions - Hepatitis A vaccine to group 1 (54 volunteers) at 0,1 , and 2 months and to group 2 (50) at 0,1 , and 6 months.

Main outcome measures-Symptoms at and after each dose; liver function, hepatitis $A$ virus specific serum immune response; and responses in saliva and parotid fluid in immunised volunteers and subjects with natural immunity.

Results-The vaccine was well tolerated; $97 \%$ $(96 / 99)$ and $100 \%$ of those immunised developed serum antibody after one and two doses of vaccine respectively. Geometric mean titres increased progressively after each dose and were significantly higher in men but not women in group 2 after the third dose (ratio between geometric mean titres $0 \cdot 265,95 \%$ confidence interval 0.18 to 0.39 ; $\mathbf{p}<\mathbf{0 . 0 0 0 1}$ ). At one year this group-sex interaction was absent; geometric mean titres for both sexes were significantly higher in group 2 (ratio 0.330 , 0.227 to $0.478 ; p<0.0001$ ). Antibody responses were not significantly different between the groups at two years. Compared with naturally infected subjects immunised volunteers developed poor or undetectable virus specific IgG and IgA responses in saliva and parotid fluid.

Conclusions-The vaccine was safe and highly immunogenic, and the differences in the immune responses in saliva and parotid fluid are unlikely to affect its efficacy.

\section{Introduction}

The first hepatitis A vaccine, comprising formalin inactivated virus extracted from marmoset liver, was shown to be both immunogenic and protective in marmosets as long ago as $1978 . .^{\prime}$ It was not until the following year, however, that hepatitis A virus was propagated in tissue culture, ${ }^{2}$ making large scale vaccine production feasible. Owing to poor yield of virus in cell culture and because until recently priority has been given to other vaccines, particularly hepatitis $B$ vaccine, it is only now, more than a decade later, that a hepatitis A vaccine is available in the United Kingdom.

Although hepatitis A virus does not lead to chronic liver disease and is frequently subclinical in young subjects, infection can be severe, with fulminant hepatic failure, particularly in older persons. In the United Kingdom, for example, hepatitis A is responsible for about a fifth of cases of fulminant viral hepatitis, ${ }^{3}$ and a mortality of $1.5 \%$ in subjects aged over 64 has been recorded. ${ }^{4}$ Furthermore, a prolonged or relapsing course is recognised, ${ }^{56}$ and it has recently been suggested that hepatitis A virus may act as a trigger for autoimmune chronic active hepatitis in susceptible subjects. ${ }^{7}$

Over the past few years considerable effort has been directed towards developing live attenuated ${ }^{89}$ and inactivated $^{10}$ hepatitis $\mathrm{A}$ vaccines. An inactivated hepatitis $A$ vaccine has just become available, and we describe a trial of a formalin inactivated whole virus hepatitis A vaccine in adult volunteers, comparing immunogenicity in two different schedules. In addition, we compare salivary and parotid antibodies in immunised volunteers and people with natural immunity and discuss the potential use of this vaccine both in the United Kingdom and in developing countries.

\section{Subjects and methods} HEPATITIS A VACCINE

The vaccine was prepared from the HM175 strain (RIT 4380) grown on MRC-5 cells. Virus was purified by ultrafiltration and gel chromatography, inactivated with formaldehyde, and adsorbed on to aluminium hydroxide. ${ }^{11}$

Each $1 \mathrm{ml}$ dose of vaccine contained 720 ELISA (enzyme linked immunosorbent assay) units of killed hepatitis $\mathrm{A}$ virus, measured by means of a capture ELISA. ${ }^{11}$

\section{VOLUNTEERS}

One hundred and five healthy adult volunteers (medical students, doctors, and laboratory staff) gave written informed consent to participate in the trial, which had local ethical approval. Analyses of reactogenicity and immunogenicity were carried out on 104; one volunteer was excluded owing to an irregular immunisation schedule. Table I summarises the demographic details of the volunteers. All volunteers were negative for hepatitis A virus specific IgG and they were aged between 19 and 60 years (mean and median ages 30.8 and 29 respectively); 71 were men and 33 were women.

\section{TRIAL PROTOCOL}

We stratified the volunteers according to age $(>30$ and $<30$ ) and sex into four groups. Within each group the subjects were allocated randomly into one of two vaccine schedules: group 1 to receive vaccine at 0 , one, and two months and group 2 at 0 , one, and six months. The dose schedules selected were those in current use 